\title{
SPATIAL MEASUREMENTS OF SNOWMELT FLOOD BY IMAGE ANALYSIS WITH MULTIPLE- ANGLE IMAGES AND RADIO-CONTROLLED ADCP
}

\author{
Ichiro FUJITA 1 , Masaki KITADA ${ }^{2}$, Mitsuru SHIMONO² ${ }^{3}$ Takashi KITSUDA ${ }^{4}$, Atsu- \\ hiro YOROZUYA ${ }^{5}$ and Yoshiki MOTONAGA ${ }^{6}$ \\ ${ }^{1}$ Member of JSCE, Professor, Dept. of Civil Eng., Kobe University \\ (1-1 Rokkodai-cho, Nada-ku, Kobe 657-8501, Japan) \\ E-mail: ifujita@kobe-u.ac.jp \\ ${ }^{2}$ Member of JSCE, Graduate student, Dept. of Civil Eng., Kobe University \\ (1-1 Rokkodai-cho, Nada-ku, Kobe 657-8501, Japan) \\ E-mail: markorange0418@gmail.com \\ ${ }^{3}$ Member of JSCE, Graduate student, Dept. of Civil Eng., Kobe University \\ (1-1 Rokkodai-cho, Nada-ku, Kobe 657-8501, Japan) \\ E-mail:mtr.0802@gmail.com \\ ${ }^{4}$ Member of JSCE, President, Hydro Systems Development, Inc. (3-2-18 Honden, Nishi-ku, Osaka 552-0022, Japan) \\ E-mail: t-kitsuda@hydro-sys.com \\ ${ }^{5}$ Member of JSCE, Researcher, International Centre for Water Hazard and Risk Management \\ under the auspices of UNESCO (ICHARM) Public Works Research Institute \\ (1-6 Minamihara, Tsukuba, Ibaraki 305-8516, Japan) \\ E-mail: yorozuya@pwri.go.jp \\ ${ }^{6}$ Member of JSCE, Researcher, Research Division 2nd, Foundation of River \& Basin Integrated \\ Communications, JAPAN (1-3 Kojimachi, Chiyoda-ku, Tokyo 102-8474, Japan) \\ E-mail: y-motonaga@river.or.jp
}

\begin{abstract}
Measurements of flood flow have been conducted intensively at major control sections in Japan for storing reliable hydrological data for use in a long-term river planning. However, such a measurement pays attention only to flow passing through one cross-section; thus, spatial flow features are not available, while river channel changes its feature at every flood event. In this research, we performed concurrent measurements of a snowmelt flood of the Uono River using an image analysis and radio-controlled acoustic Doppler current profiler (ADCP). In the image analysis with STIV (Space-time Image Velocimetry), three video cameras were used to cover a river reach of about $300 \mathrm{~m}$ by changing their view angles at every location. On the other hand, the boat-mounted ADCP was remotely controlled to form a zigzag trajectory to cover the same reach. The accuracy and limitation of STIV was made clear through a comparison with ADCP data and a spatial distribution of correction factor from surface to depth-averaged velocity was found to have a weak correlation with a large-scale bed slope.
\end{abstract}

Key Words : STIV, image analysis, radio-controlled ADCP, surface flow measurement, river flow structure

\section{INTRODUCTION}

In recent years, a large number of river monitoring cameras have been installed in Japan, which sometimes happened to record rare and important images of very large floods. From such images, we can recognize that the actual flood flow is very complicated and varies significantly in space and time; moreover it is usually quite difficult to extract flow information such as velocity distribution or discharge from such images. Although recently developed numerical simulation techniques can provide useful information about flows, the level of accuracy of the results is not always satisfactory because the actual boundary conditions are too complicated to be applied accurately in the simulation. For example, simulated two-dimensional velocity distributions are usually provided without a comparison with 


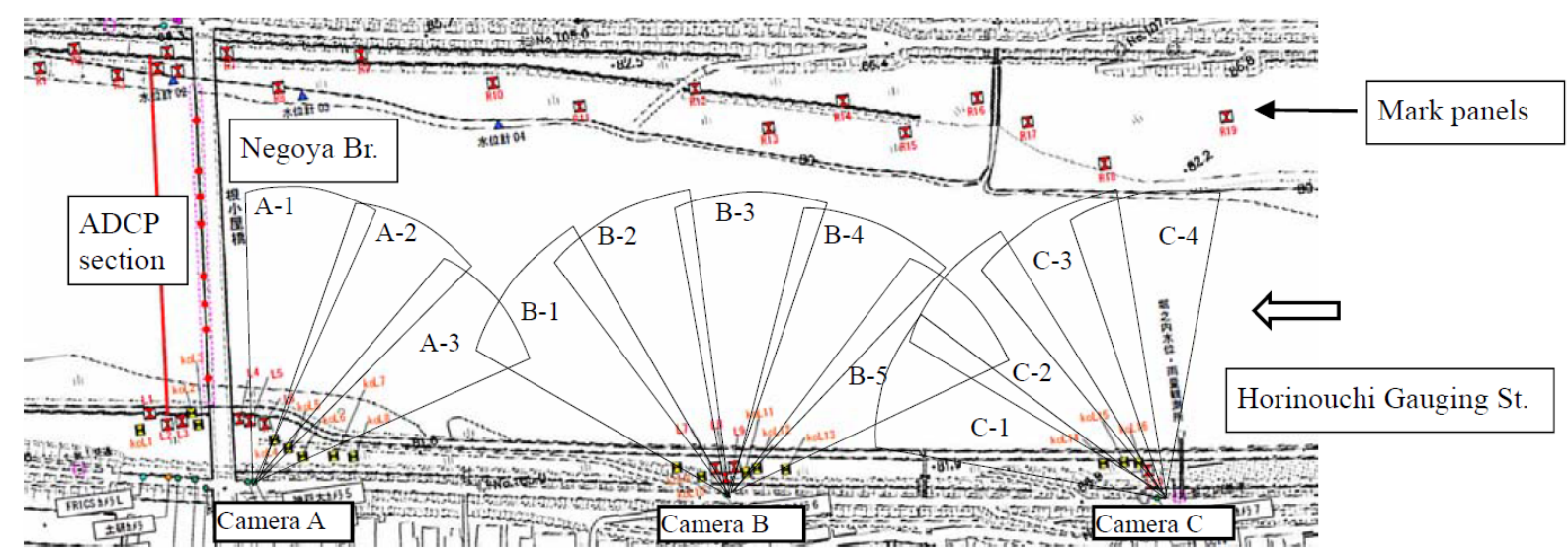

Fig.1 Measurement site and angles for image shooting.

measured data because measurement techniques for obtaining spatial velocity distribution are not available so far. Therefore, strictly speaking, the simulated results have been discussed only qualitatively but not quantitatively in previous researches with respect to velocity variations.

Among flow measurement methods, several techniques have been proposed to measure a cross-sectional velocity distribution mainly for the purpose of obtaining river discharge flowing through a section. At the same time measurement accuracies have come to be compared between several methods ${ }^{1)}$. Typical techniques include boat-mounted ADCP towed along a bridge to measure internal velocity distribution ${ }^{2), 3)}$, imaging techniques to measure surface velocity distributions ${ }^{4)-6}$, and radio wave velocity meters installed at a bridge to measure surface velocity at several spots in front of the equipment $^{7}$. The advantage of imaging techniques is that they do not require a bridge for measurements, but a manned boat-mounted ADCP can also be used to cover a long measurement reach without a bridge if the surface velocity is not that high. Regarding the usage of ADCP, Tsubaki et al. ${ }^{8)}$ proposed an efficient interpolation method to extract a three-dimensional flow structure from measurement data at various sections passing through the same water zone. Recently, radio-controlled boat-mounted ADCPs have been available for measuring arbitrary cross-sections $^{9), 10)}$.

Regarding spatial measurement of river surface flows, Fujita et al. ${ }^{11)}$ succeeded in obtaining a wide range of surface velocity distributions of the Uji River by analyzing video images captured from a steel tower for meteorological observations with the large-scale particle image velocimetry (LSPIV) technique $^{12)}$. The measurements were conducted from a 60-meter-high deck of the tower by changing the horizontal shooting angles to cover about 100 -meter river reach including several groins. In the other cases, video images taken from a helicopter

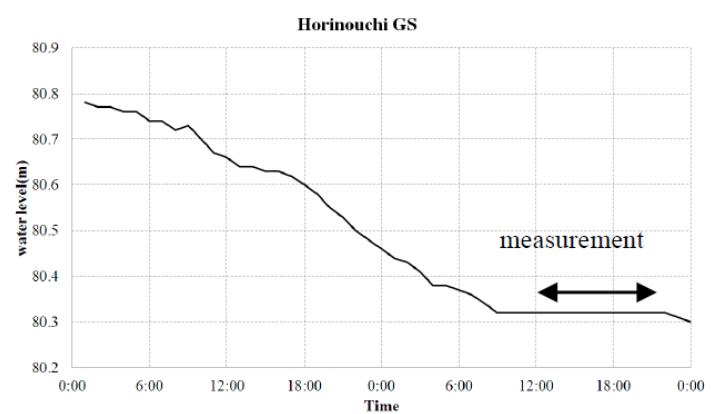

Fig.2 Water level hydrograph.

were used to analyze surface flows: Fujita and Hino ${ }^{13)}$ first analyzed video images of the 2000 Shinkawa River flood where bank breach took place. Etoh et al. ${ }^{14)}$ visualized the surface flow of the Uji River in normal flow condition with rice cracker tracers and analyzed the flow with the particle tracking velocimetry (PTV). Fujita and Kunita ${ }^{15)}$ obtained the surface velocity distributions of river reaches spanning several kilometers of the Yodo River and its tributary rivers and examined discharge balances before and after the confluence. Fujita and Kunita $^{15)}$ termed such a method of measurement the aerial LSPIV.

As can be seen from the above measurements by ADCP or aerial LSPIV, the previous researches were conducted independently without a comparison with other techniques. Therefore, in this research, we took measurements of a snowmelt flood of the Uono River, a tributary of the Shinano River, concurrently with a radio-controlled boat-mounted ADCP and space-time image velocimetry (STIV) ${ }^{16)}$ in order to examine the measurement accuracy.

\section{OUTLINE OF FIELD MEASUREMENT}

The measurements at the Uono River were conducted from April 19 to April 21 in 2013 as a joint research among the Committee on Hydroscience and Hydraulic Engineering JSCE, the International Cen- 


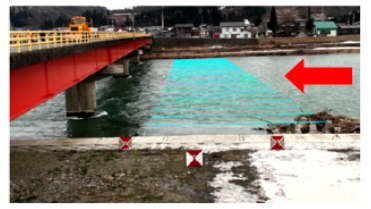

(1)A-1(18.8m,5.38m)

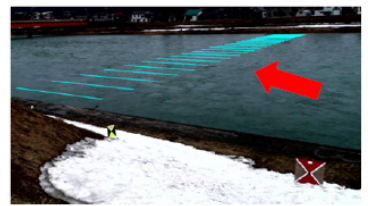

(5) B-2 $(15.8 \mathrm{~m}, 5.54 \mathrm{~m})$

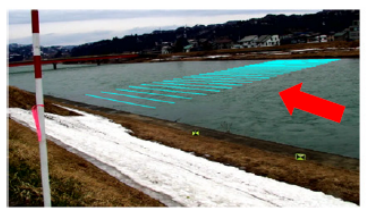

(9) $\mathrm{C}-1(38.7 \mathrm{~m}, 4.42 \mathrm{~m})$

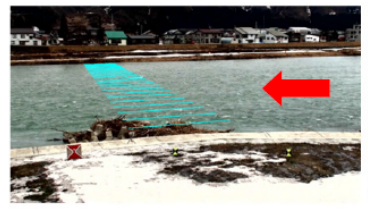

(2)A-2(12.8m,5.5m)

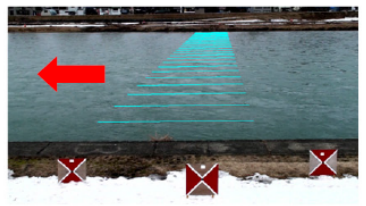

(6) B-3(11.7m, $4.71 \mathrm{~m})$

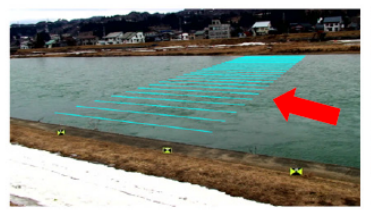

(10) C-2 $(24.5 \mathrm{~m}, 4.42 \mathrm{~m})$

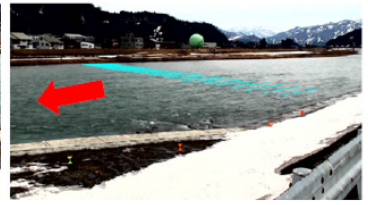

(3)A-3(20.1m,5.38m)

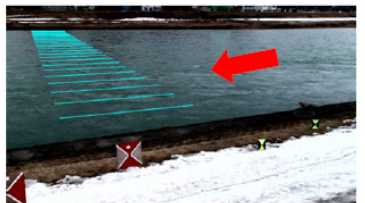

(7) B-4(11.2m, $4.79 \mathrm{~m})$

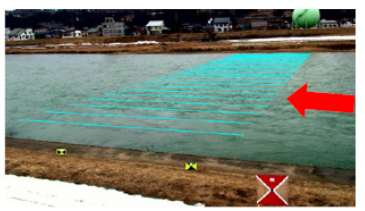

(11) $\mathrm{C}-3(24.5 \mathrm{~m}, 4.3 \mathrm{~m})$

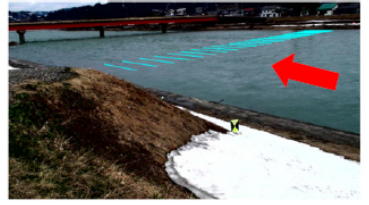

(4) B-1 $(15.7 \mathrm{~m}, 5.75 \mathrm{~m})$

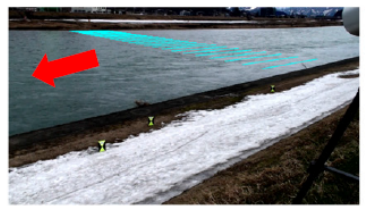

(8) B-5(22.3m,4.79m)

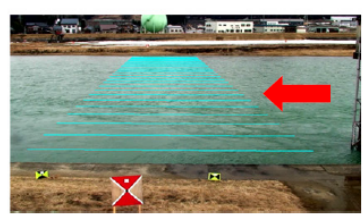

(12) C-4(21.3m, $4.38 \mathrm{~m})$

Fig.3 Typical images of the respective angles and the search lines for STIV measurement; the first numerical value in the parentheses is the physical length of the search line and the second value is the spacing between the search lines.

tre for Water Hazard and Risk Management under the auspices of UNESCO (ICHARM), and Kobe University. The results to be presented hereafter were obtained on April 20. The target zone for the present measurement is a 300-meter reach upstream of the Negoya Bridge at Horinouchi in Uonuma City, Niigata Prefecture. Figure 1 shows the outline of the measurement site and various angles of image shooting. Measurements by towing ADCPs, radio wave velocity meters, and STIV were also conducted at the section just downstream of the Negoya Bridge. The water level during the measurement on April 20 was almost constant for half a day as shown in Fig.2, which enabled us to measure a longer river reach by a radio-controlled ADCP in a zigzag manner for measurements under the same flow condition.

\section{(1) Image shooting by video cameras}

The image shooting for the flow was carried out from the three locations on the left bank indicated in Fig.1. The distance between Camera A and Camera $\mathrm{C}$ was about 300 meters. The image shooting was executed by rotating the video camera on a tripod step by step to cover the entire water surface zone visible from each camera. Thirteen mark panels measuring $90 \mathrm{~cm}$ by $90 \mathrm{~cm}$, which were used as ground control points (GCPs), were vertically set on the other side of the floodplain at an almost constant spacing in a zigzag manner. On the other hand, smaller-sized mark panels measuring $30 \mathrm{~cm}$ by $40 \mathrm{~cm}$ were additionally placed together with larger ones so that each field of view could include at least six GCPs. The location of GCPs in the physical and screen coordinates were used to establish a mapping relation between the coordinates with the information on water level.

The image shooting was carried out for several minutes every hour from 10:00 a.m. until 6:00 p.m. by rotating the video camera to the specified direction every time. As shown in Fig.1, Camera A covers three angles from A-1 to A-3 just upstream of the bridge, Camera B covers five angles from B-1 to B-5 in the intermediate reach, and Camera $\mathrm{C}$ takes care of four angles from $\mathrm{C}-1$ to $\mathrm{C} 4$ just downstream of a gauging station. Although the repeatability of the respective angle was not perfect, each direction was set to reproduce the same field of view as much as possible.

\section{(2) Measurement of surface velocity by STIV}

In STIV, streamwise velocity spatially and temporally averaged along a search line set in the direction of the main flow can be measured first by generating a space-time image (STI) for each search line ${ }^{16)}$. STIs are constructed by piling up the image intensity distribution (IID) along a search line taking IID as the horizontal axis and the number of image frame, i.e., time, in the vertical axis. When water surface ripples are generated by river turbulence being advected with the surface flow, they appear as a striped oblique pattern in the STI. The advantage of STIV is that the velocity along the search line can be obtained simply by measuring the gradient of the pattern even manually. Normally, image shooting is done along the flow for the purpose of estimating river discharge at the section. However, in this re- 


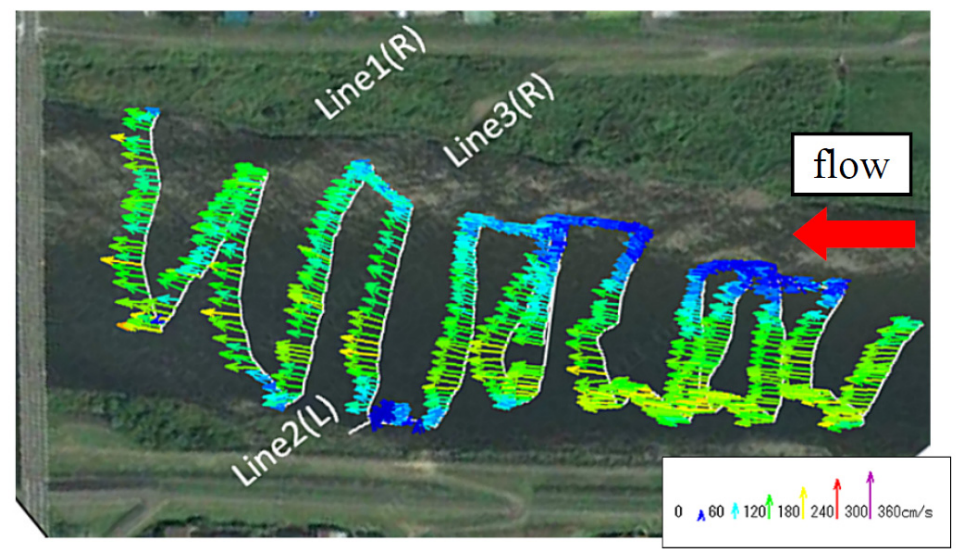

Fig.4 Trajectories and surface velocity vectors measured by remote-controlled ADCP.

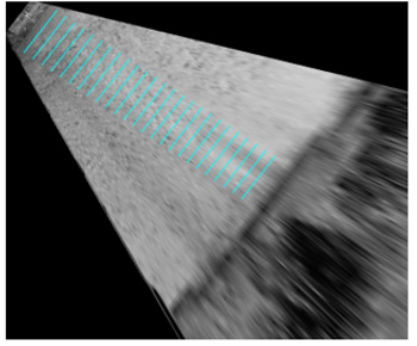

(a) rectified image

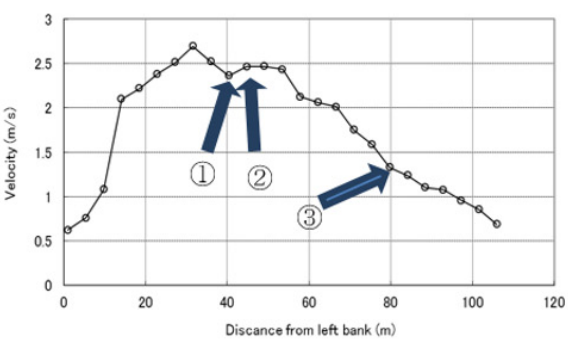

(b) velocitv distribution

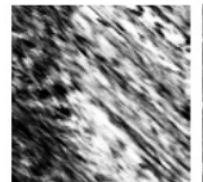

(1) $342 \times 300$ pix $2.36 \mathrm{~m} / \mathrm{s}$

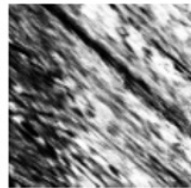

(2) $322 \times 300$ pix $2.47 \mathrm{~m} / \mathrm{s}$

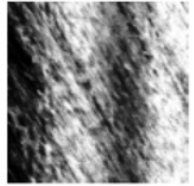

(3) $210 \times 300$ pix $1.38 \mathrm{~m} / \mathrm{s}$

(c) example of STI; horizontal scale is $21.3 \mathrm{~m}$ and vertical scale is 10 seconds

Fig.5 Example of measurement results by STIV for angle C-4.

search, surface images of farther zones were intentionally taken from skewed angle in order to examine the accuracy and limitation of the STIV technique. Typical images with search lines for the respective angle are provided in Fig.3. The first and the second numerical values in the parentheses stand for the search line length and the spacing between search lines, respectively.

As can be seen in the angles A-1, B-1, and C-1 in Fig.3, the Negoya Bridge is visible in the left-most side of the image but when we pay attention to the section just upstream of the bridge, the spatial resolution is quite different for each case. For example, the surface pattern at such a section cannot be recognized in the angle $\mathrm{C}-1$, suggesting that there should be some limitation in the STIV measurement for a section farther from the camera. In the latter section, a rough estimate of measurement accuracy will be proposed.

\section{(3) Measurement by remote-controlled ADCP}

In river measurements, acoustic Doppler current profilers are usually installed a small boat and towed back and forth along the bridge in order to obtain river discharges. However, since this method requires a bridge for towing, it is impossible to measure spatial flow data. It is possible to measure a long reach of data if we use a manned boat with ADCP, however, it is impossible to measure under fast flood flow conditions because navigation will be dangerous. To solve such a problem, remote-controlled ADCPs have become available in recent years. The first such trial was conducted by Kinoshita and Nakano ${ }^{17)}$ before manufactured instruments were released. At present, several new products are available that can be used under the maximum velocity of about $3 \mathrm{~m} / \mathrm{s}$. In fact, we tried to use such an instrument in the last year's trial at the same location, but since the maximum velocity was more than $3.5 \mathrm{~m} / \mathrm{s}$, it was difficult to use under such a high-speed flow. On the other hand, as the maximum velocity was about $3.0 \mathrm{~m} / \mathrm{s}$ this year due to a smaller discharge, it was possible to cover a long river reach by controlling the river boat in a zigzag manner. Figure 4 shows the trajectory of the radio-controlled boat and velocity vectors nearest to the water surface. The measurement mode of ADCP was a high-speed sampling mode with 40 layers and a thickness of $0.1 \mathrm{~m}$ with the first layer thickness of $41 \mathrm{~cm}$. The main ping was two and the sub-ping was ten. The nominal accuracy measured by a standard deviation was $6.95 \mathrm{~cm} / \mathrm{s}$ and the duration of measurement was 1.6 seconds. The measurement was executed from 13:37 till 14:13 on April 20 by taking three trajectories as 


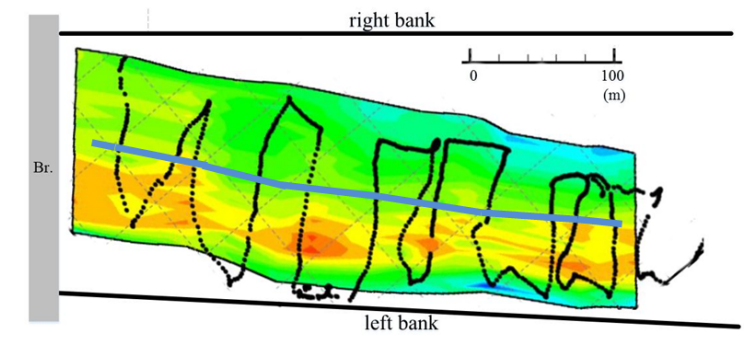

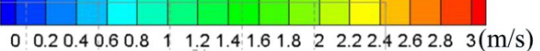

Fig.6 Measurement results by STIV and trajectories of ADCP.

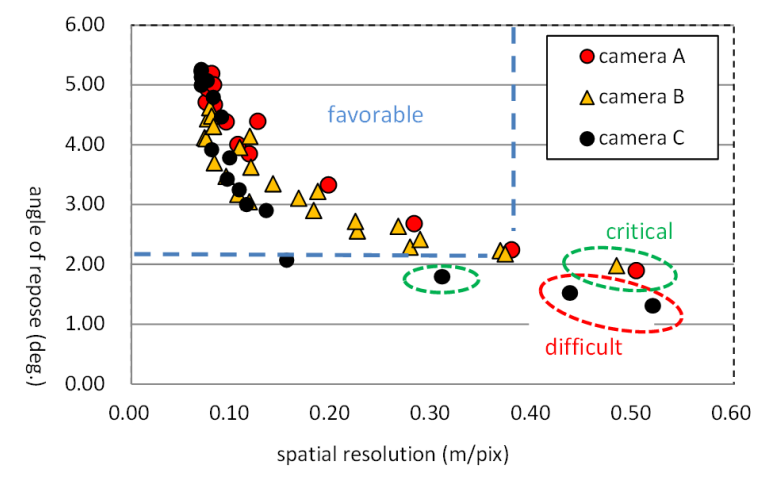

Fig.7 Criteria for STIV measurement.

indicated in Fig.4. The length of the trajectory was about two kilometers and the streamwise distance was about 300 meters. The boat was controlled with great care to avoid hitting the side banks.

\section{RESULTS AND DISCUSSIONS}

In this section, velocity distributions obtained by STIV and ADCP are mainly compared along with the estimation of internal flow structures.

\section{(1) Surface velocity distribution measured by STIV}

Figure 5 shows the typical results measured by STIV for the angle C-4. A rectified image, streamwise velocity distribution, and three representative STIs are indicated. There are 25 search lines with a length of $21.3 \mathrm{~m}$ and a spacing of $4.4 \mathrm{~m}$, covering about $110 \mathrm{~m}$ of water surface width. The angle of repose to the farthest search line is 2.94 degrees and the nearest one is 18.88 degrees. As is evident from Fig.5(c), each STI exhibits clearly inclined straight features suggesting that the surface ripples were advected at a constant speed at least for about ten seconds while passing through each search line. It is seen from Fig.5(b) that the velocity distribution is skewed with the maximum velocity appearing nearer to the left bank. The maximum velocity at this section is $2.7 \mathrm{~m} / \mathrm{s}$, which falls within the range of the performance limitation of the present ADCP measure-

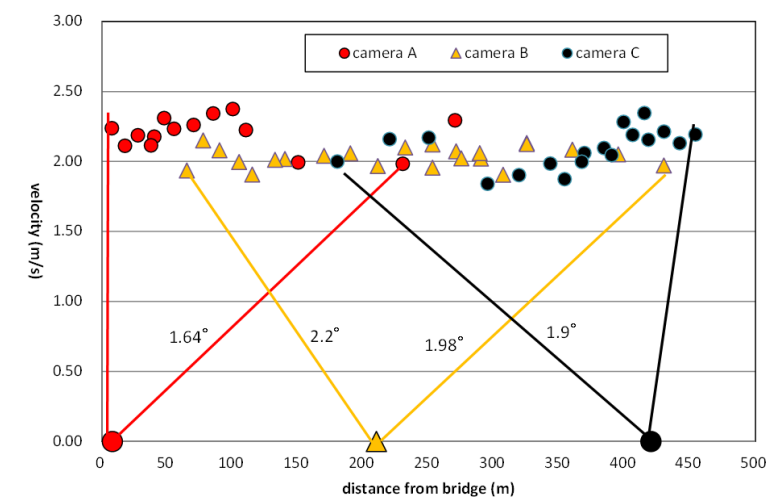

Fig.8 Longitudinal velocity variation from different angles.

ment. Similar STIV analysis was executed for all of the angles indicated in Fig.3. The STIV results two-dimensionally interpolated are shown in Fig.6 together with the ADCP trajectory. It is obvious that the faster flow region is generally shifted nearer to the left bank and the higher velocity area spreads transversely just upstream of the bridge. Measured minimum velocity was $0.5 \mathrm{~m} / \mathrm{s}$ and the maximum velocity was $2.9 \mathrm{~m} / \mathrm{s}$. The minimum angle of repose towards the center of a search line was 2.4 degrees. The shift of the main flow nearer to the left bank was due to a large bend of the river course upstream of the measurement region.

\section{(2) Measurement criteria of STIV}

In the STIV results shown in Fig.6, each STI displayed clearly oblique features even when the angle of repose was about three degrees for a distance of about 150 meters from the camera, yielding no serious problems in the analysis. However, it is obvious that there exist some limitations in the STIV analysis in terms of the angle of repose or the distance from the camera when we try to use it for a wider river. In order to examine measurement limitations, measurements at the same location were conducted intentionally viewed from three different angles. For that purpose, we assumed a longitudinal line as drawn in Fig.6 and applied STIV for many search lines set along the above line to compare the longitudinal velocity distribution. In applying STIV, the angle of repose for the center of the search line, as well as the size of one pixel in the direction of the search line was obtained.

Figure 7 provides the relation between the angle of repose and the spatial resolution at various measurement points together with the respective quality of STI categorized as "favorable" when the pattern is clear, "critical" when the pattern is rather vague, and "difficult" if the pattern is too vague to identify the oblique feature. Although STIV is intrinsically a robust technique, it is rational to consider that its performance deteriorates as the spatial resolution 


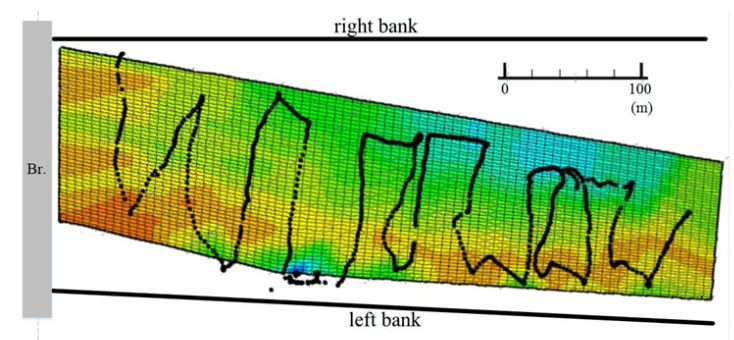

$\begin{array}{llllllllllll}0 & 0.20 .40 .6 & 0.8 & 1 & 1.21 .41 .61 .8 & 2 & 2.22 .42 .62 .8 & 3(\mathrm{~m} / \mathrm{s})\end{array}$

Fig.9 Subsurface velocity distribution measured $41 \mathrm{~cm}$ below the water surface by ADCP.

becomes lower. From Fig.7, the criteria for a proper measurement by STIV can be considered to be more than about two degrees in the angle of repose and less than $0.4 \mathrm{~m}$ per pixel in spatial resolution. However, in the actual situation, surface features are detectable if the spatial resolution is high enough even when the angle of repose is smaller than two degrees. Therefore, we propose, as a rough criterion for STIV measurements, less than $0.4 \mathrm{~cm}$ as a spatial resolution. Figure 8 plots all of the data classified as favorable. It can be seen that there still remain some relative errors for data obtained farther from the camera; therefore, further examinations are necessary with respect to measurement accuracy.

\section{(3) Comparison of surface velocities by ADCP and STIV}

Figure 9 shows the interpolated velocity distribution nearest to the water surface, $41 \mathrm{~cm}$ below the surface, measured by the radio-controlled ADCP. In the two-dimensional interpolation, the target area was divided into 80 by 50 mesh points and for each mesh a circle with increasing diameter is assumed so that more than five data can be included in the circle. The data picked up within the circle are averaged with weights inversely proportional to the distance.

Comparing the data shown in Fig.9 with the STIV results provided in Fig.6, the overall spatial distribution agrees fairly well except the data nearer to the bank. This is because the remote-controlled ADCP is difficult to use to measure the flow close to the bank and thus only the higher velocity values nearer to the main flow were used in the interpolation.

Figure 10 provides more quantitative comparisons between STIV and ADCP taking transverse velocity distributions for the angles A-2, B-2, and B4 as an examples. Allowing some relative scatters, fair agreements between the two methods can be seen for each angle. The sources of errors are caused by a rough interpolation using a small number of ADCP data and the difference in height in the ADCP measurement at $41 \mathrm{~cm}$ below the water surface while STIV measures surface data.
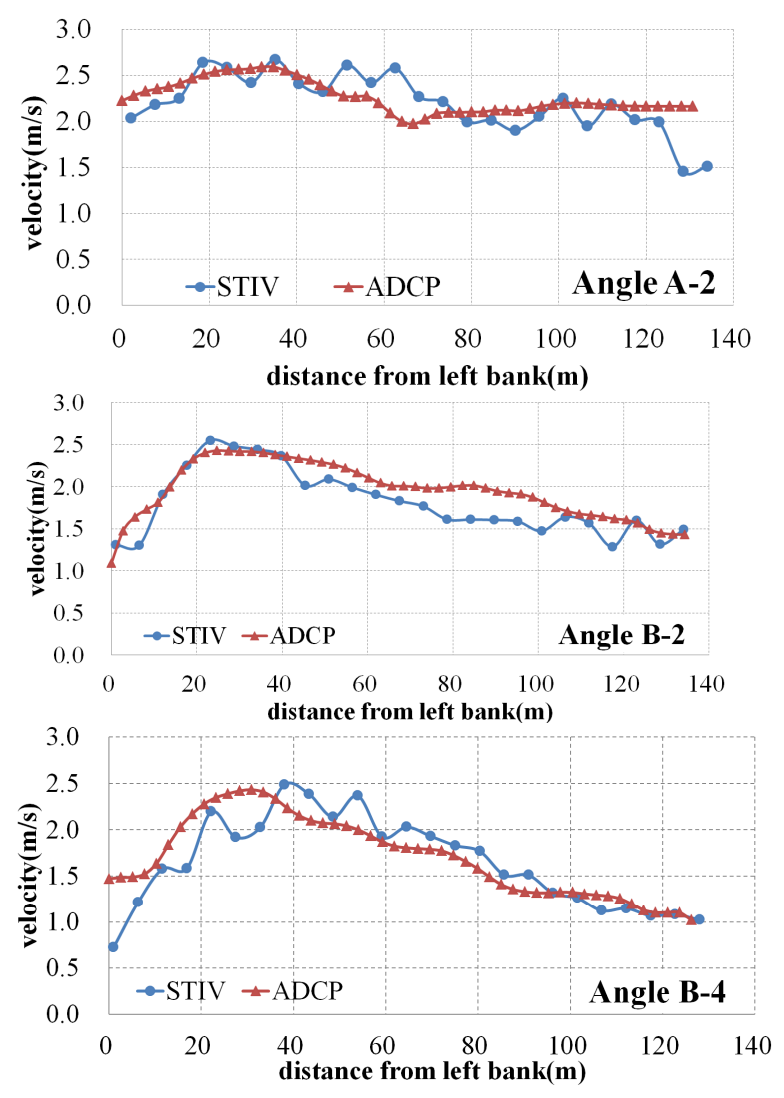

Fig.10 Comparison of surface or near-surface velocity distributions at three cross-sections.

\section{(4) Subsurface flow structure by ADCP}

Regarding the ADCP data of internal flow velocities and bed level along the trajectories, the two-dimensional interpolation as used in processing Fig.9 was applied to obtain respective spatial distributions as well. Figure 11 shows water depth variations for the same area after applying a moving average method for smoothing the values. It is clearly seen that the thalweg shifts nearer to the left bank and the water depth becomes shallower closer to the bridge probably due to the deposition of bed materials by a backwater effect at the bridge. The longer local scour area near the upstream left bank may be due to the effect of the gauging station standing just upstream of the area.

Finally, a distribution of the correction coefficient calculated from vertical velocity distributions interpolated at each mesh and STIV data is provided in Fig.12. The correction coefficient is obtained by dividing a depth-averaged velocity with a surface velocity at the same location. Since the water depth varies at every mesh, we assumed a power low of velocity profile near the bottom layer with a height of ten percent of the water depth. Figure 12 shows that the average value is about 0.85 which is a typical value usually observed in rivers. It can be noted that the value slightly decreases in the shallower region just upstream of the bridge. The reason for this de- 

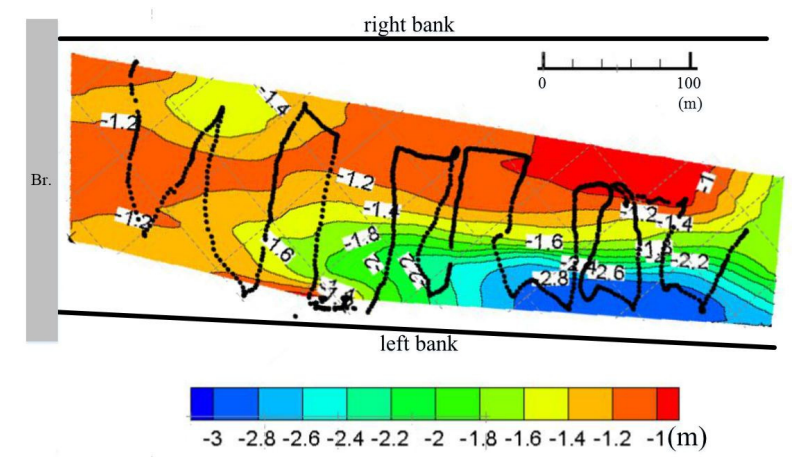

Fig.11 Distribution of water depth variation after interpolation of ADCP data.

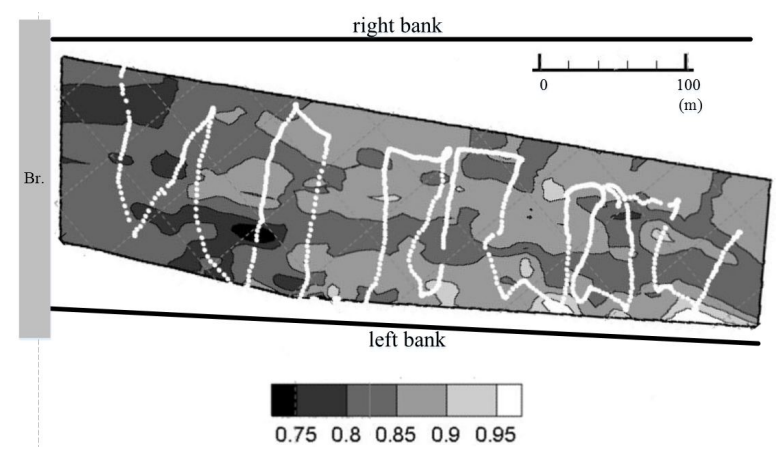

Fig.12 Distribution of correction coefficient obtained by STIV and ADCP measurements.

crease is that a lower velocity zone subject to bed roughness effect close to the bed does not change significantly when the water depth decreases from a deeper region and yields a relative increase of decelerated flow height. However, further examination is required for the estimation of the distribution of the correction coefficient.

\section{CONCLUSIONS}

In this research, spatial river flow measurements by using two totally different methods, STIV and ADCP, were concurrently executed targeting the snowmelt flood of the Uono River. A river reach of about 300 meters was mainly observed by using three cameras in STIV and a remote-controlled ADCP navigated to cover the same region in a zigzag manner. The surface velocity distribution in the river reach was successfully measured by STIV changing a field of view step by step and the results agreed fairly well with those data nearest to the water surface measured by the ADCP. A criterion for STIV measurement was also proposed. An efficient interpolation method was proposed together with the treatment method of near- bottom ADCP data. It should be noted that, from the combined results by STIV and ADCP, a distribution of correction coefficient was first obtained, suggesting the influence of relative water depth to the coefficient. However, more field observations were required to obtain more general results in terms of the correction coefficients.

ACKNOWLEDGMENT: This paper is an outcome of the joint project by the Committee on Hydroscience and Hydraulic Engineering JSCE, ICHARM, and Kobe University. Many companies also supported the actual measurements and field survey. We are grateful for their great efforts and support in this research.

\section{REFERENCES}

1) Fujita, I., Kosaka, Y., Yorozuya, A. and Motonaga, Y. : Surface flow measurement snow melt flood by using a far infrared camera, Journal of Japan Society of Civil Engineers, Ser. B1 (Hydraulic Engineering), Vol. 69, No. 4, pp.I_703-I_708, 2013 (in Japanese).

2) Yorozuya, A., Okada, S., Kitsuda, T., Sugano, Y. and Fukami, K.: Proposal of tethered ADCP platform for high-speed flow measurements, Advances in River Engineering, JSCE, Vol. 16, pp. 59-64, 2010 (in Japanese).

3) Okada, M., Yorozuya, A., Kitsuda, T., Sugano, Y. and Fukami, K.: Discussion of accuracy evaluation methods for flood flow observation by towing ADCP, Journal of Japan Society of Civil Engineers, Ser. B1 (Hydraulic Engineering), Vol. 67, No. 4, pp. I_1183-I_1188, 2011 (in Japanese).

4) Muste, M., Fujita, I. and Hauet, A.: Large-scale particle image velocimetry for measurements in riverine environments, Water Resources Research, Vol. 44, W00D19, doi:10.1029/2008WR006950, 2008.

5) Fujita, I. and Komura, S.: Application of video image analysis for measurements of river-surface flows, Annual Journal of Hydraulic Engineering, JSCE, Vol. 38, pp. 733-73, 1994 (in Japanese).

6) Fujita, I. : Measurement of river flow by non-contact techniques and the related problems, Journal of Japan Society of Fluid Mechanics, Vol. 26, pp. 5-12, 2007 (in Japanese).

7) Yamaguchi, T. and Niizato, K.: Flood discharge observation using radio current meter, Journal of Japan Society of Civil Engineers, JSCE, No. 497/II-28, pp. 41-50, 1994 (in Japanese).

8) Tsubaki, R., Kawahara, Y., Muto, Y. and Fujita, I.: New 3-D flow interpolation method on moving ADCP data, Water Resources Research, Vol. 48, W05539, doi: 10.1029/2011WR010867, 2012.

9) Kitsuda, T., Okada, S., Arai, R., Shimoda, C. and Deguchi, T.: Speculation of measurement accuracy evaluation method for moving observation using radio-controlled boat equipped with ADC, Advances in River Engineering, JSCE, Vol. 14, pp. 295-300, 2008.

10) Okada, S., Kitsuda, T., Morimoto, S. and Masuda, M.: Flood flow observation in Shimanto River Gudo point using unmanned boat equipped with ADCP, Annual Journal of Hydraulic Engineering, JSCE, Vol. 52, pp. 919-924, 2008 (in Japanese).

11) Fujita, I., Mutoh, Y., Shimazu, Y., Tsubaki, R. and Aya, S.: Velocity measurements around non-submerged and submerged spur dykes by means of large-scale particle image velocimetry, Annual Journal of Hydraulic Engineering, JSCE, Vol. 47, pp. 943-948, 2003 (in Japanese).

12) Fujita, I., Muste, M. and Kruger, A.: Large-scale particle image velocimetry for flow analysis in hydraulic engineering applications, Journal of Hydraulic Research, Vol. 36, No. 3, pp. 397-414, 1998.

13) Fujita, I. and Hino, T.: Unseeded and seeded PIV meas- 
urements of river flows videotaped from a helicopter, Journal of Visualization, Vol. 6, No. 3, pp. 245-252, 2003.

14) Etoh, T., Takehara, K., Takano, Y., Okuno, S., Fujita, I. and Sakai, N. : A case study on application of PTV to measurement of surface flow fields of rivers as a local remote sensing technology, Journal of Japan Society of Civil Engineers, JSCE, No. 796/II-72, pp. 39-52, 2005 (in Japanese).

15) Fujita, I. and Kunita, Y.: Application of aerial LSPIV to the 2002 flood of the Yodo River using a helicopter-mounted high-density video camera, Journal of Hydro-Environment Research, Vol. 5, Issue 4, pp. 323-331, 2011.
16) Fujita, I., Watanabe, H. and Tsubaki, R.: Development of a non-intrusive and efficient flow monitoring technique: The space time image velocimetry (STIV), International Journal of River Basin Management, Vol. 5, No. 2, pp. 105-114, 2007.

17) Kinoshita, R. and Nakao, T.: Measurement of river discharge by ADCP and observation of river hydraulic structure, JSCE Magazine Civil Engineering, Vol. 92, No. 10, pp. 68-71, 2007 (in Japanese).

(Received March 31, 2015) 